\title{
Theoretical and Experimental Study of New Dihydroorotate Dehydrogenase and Tryparedoxin Peroxidase Inhibitors: One More Step in the Study of Leishmaniasis Infection
}

\section{Roger Espinosa-Saez}

University of Córdoba

\section{Sara M. Robledo}

University of Antioquia

Tatiana Pineda

University of Antioquia

Javier Murillo

University of Antioquia

Gilmar Santafé Patiño

University of Córdoba

\section{César Zúñiga}

University of the Americas

\section{Osvaldo Yañez}

Andrés Bello University

\section{Plinio Cantero-López}

Andrés Bello University

Camilo Guzmán ( $\square$ cantonioguzman@correo.unicordoba.edu.co )

University of Córdoba

\section{Research Article}

Keywords: Antileishmanial Activity, 2-arylquinolines, in silico studies, computational docking, ADMET properties

Posted Date: November 29th, 2021

DOI: https://doi.org/10.21203/rs.3.rs-1056733/v1

License: (c) (i) This work is licensed under a Creative Commons Attribution 4.0 International License. Read Full License 


\section{Abstract}

In this study, the viability of new dihydroorotate dehydrogenase and tryparedoxin peroxidase inhibitors is reported. In vitro antileishmanial activity was evaluated using a Leishmania (V) panamensis strain, and the cytotoxicity of the compounds was assessed using U-937 cells. The in vivo therapeutic response was evaluated in golden hamsters (Mesocricetus auratus) experimentally infected with L. (V) panamensis and treated with a $1 \%$ topical formulation of compounds $4 a-f$. On the other hand, in silico studies considering the synthesized compounds were also carried out. All of the compounds showed promising in vitro activity, with mean $\mathrm{EC}_{50}$ effective concentration values ranging from $3.8 \mu \mathrm{M}$ to $19.3 \mu \mathrm{M}$. Likewise, treatment with compounds $4 \mathrm{a}-\mathrm{f}$ produced improvement in most of the hamsters and cured some; in particular, those treated with compounds $\mathbf{4 b}, \mathbf{4 c}, \mathbf{4 d}$, and $\mathbf{4 f}$ reacted the best. Molecular dynamics (MD) simulations, computational docking, and MM/GBSA studies indicate the promising bioavailability and absorption characteristics of the studied compounds, which are expected to be orally active. In addition, the studied 2-

arylquinolines are absorbable at the blood-brain barrier, but not in the gastrointestinal tract. Finally, ADMET properties suggest that these molecules can be safely used as leishmaniasis inhibitors.

\section{Introduction}

Leishmaniasis is a neglected tropical disease that, for decades, has represented a public health problem worldwide, mainly affecting the most impoverished populations. It is endemic in about 98 countries located in the tropics and sub-tropics. The complexity of its transmission, as well as the lack of effective health policies, are the main obstacles in the control of this disease. It is caused by more than 17 species of the genus Leishmania, transmitted to humans by different species of female sand flies of the genus Phlebotomus (in the Old World) and Lutzomyia (in the New World $)^{1-3}$. According to the World Health Organization (WHO), a prevalence of approximately 12 million cases has been estimated in all forms of the infection, and around 350 million people live in areas at risk of contracting the infection [4]. Annually, about 1.5 to 2 million new cases of cutaneous leishmaniasis (CL) and mucosal leishmaniasis $(\mathrm{ML})$ are officially reported, as well as at least 0.5 million new cases of visceral leishmaniasis $(\mathrm{VL})$ and about 60,000 deaths ${ }^{4-9}$.

To date, pentavalent antimonies (Meglumine Antimoniate and Sodium Stibogluconate), together with Pentamidine Isethionate, Miltefosine, and Amphotericin B (AMB) are the drugs endorsed for the treatment of all clinical forms of leishmaniasis. However, these drugs have numerous limitations, such as the appearance of adverse effects; high toxicity in the pancreas, kidney, liver, and heart associated with prolonged therapeutic regimens with high doses; the appearance of strains with decreased sensitivity or even resistance; the high cost of the treatment; and variable efficacy, according to the strain of the parasite ${ }^{8-12}$. Therefore, it is necessary to continue the search for new drugs that are safe, effective, easy to administer, and inexpensive, in order to enable their general use and to contribute to the control of this disease.

Compounds with quinolinic nuclei belong to a group of nitrogenous heterocycles, which stand out for their great diversity of pharmacological functions (e.g., ${ }^{10,13}$ ) have highlighted their activity against protozoan parasites, such as Plasmodium falciparum ${ }^{14,15}$, with Antitrypanosomal ${ }^{5,16,17}$ and leishmanicidal activities; with respect to the latter, 8aminoquinoline (Sitamaquine) is currently used for the treatment of visceral Leishminiasis ${ }^{5}$. Likewise, 2-

styrylquinolines have shown activity against strains of Leishmania (V) panamensis ${ }^{18,19}$; likewise, formulations of quinoline derivatives have promising activity against strains of L. panamensis and L. braziliensis ${ }^{20}$. In this context, computational tools can offer useful information to interpret the trends and state structure-activity relationships, as well as allowing researchers to fully explore protein-drug interactions. For instance, molecular dynamics (MD)

Page $2 / 22$ 
simulations allow us to identify the interactions occurring along the entire potential-energy curve, by applying interatomic potentials or molecular mechanics force fields ${ }^{21,22}$. Computational docking simulation can help to predict the best orientation and conformation of drug ligands, when bound to Leishmania protein targets. The relative binding energies of ligands can be exhaustively determined using MM/GBSA studies ${ }^{23}$. Computer-Aided Prediction of Pharmacokinetic (ADMET) Properties is a modern in silico technique that helps to characterize the bioavailability, oral absorption, clearance, and volume of distribution, as well as the penetration through the blood-brain barrier of the ligands ${ }^{24}$. Under this outline, the objective of this research is to synthesize 2-arylquinoline-type compounds and evaluate their leishmanicidal activity in vitro, in vivo, and in silico, such that they can become new, more effective, safe, and easy-to-administer treatment alternatives for CL and VL.

\section{Methods}

\section{Chemistry}

The reagents and solvents used were obtained commercially from national suppliers, Merck and Sigma Aldrich. To monitor the progress of the reaction, thin-layer chromatography was used on aluminium TLC silica gel sheets $\left(60 \mathrm{~F}_{254}\right.$, Merck, Darmstadt, Germany), the Nuclear Magnetic Resonance spectra were obtained by NMR-one-dimensional ${ }^{13} \mathrm{C}$, ${ }^{1} \mathrm{H}$, and DEPT-135; two-dimensional COSY, HSQC, and HMBC-for which a $300 \mathrm{MHz}$ Bruker spectrometer was used (300 MHz for ${ }^{1} \mathrm{H}$ and 75 for ${ }^{13} \mathrm{C}$ ) using Deuterated chloroform $\left(\mathrm{CDCl}_{3}\right)$ as solvent and Tetramethyl Silane $\left[\left(\mathrm{CH}_{3}\right)_{4} \mathrm{Si}\right]$ as an internal standard. Chemical shifts $(\delta)$ are expressed in parts per million (ppm) and coupling constants $(\mathrm{J})$ in Hertz $(\mathrm{Hz})$. Silica gel 60 (0.063-0.200 mm) was used for column chromatography.

Synthesis of quinolinic derivatives $4 a-f$. For the chemical synthesis, a solution of quinaldine or 8-hydroxyquinaldine in acetic anhydride was used, the corresponding aromatic aldehyde was added. This solution was brought to reflux for 12 to 24 hours. Upon completion of the reaction, the mixture was allowed to cool to room temperature, then sodium bicarbonate was added. The mixture was extracted with a mixture of petroleum benzine/ethyl acetate. The organic phase was dried over anhydrous sodium sulphate, filtered, and concentrated under reduced pressure. Then, the crude product was purified by column chromatography (CC), using petroleum benzine/ethyl acetate with an increasing polarity gradient ${ }^{17-19}$ as eluent. The chemical structures of the compounds were corroborated by NMR spectroscopic techniques: in one dimension $\left({ }^{1} \mathrm{H},{ }^{13} \mathrm{C}\right.$, and DEPT 135) and two dimensions (COSY, HSQC, and HMBC), The individual data are described below:

2-[(E)-2-(Quinolin-2-yl)ethenyl]phenylacetate (4a) was obtained in the form of white crystals with a yield of $40 \%$; ${ }^{1} \mathrm{H}$ $\operatorname{NMR}\left(\mathrm{CDCl}_{3}, 300 \mathrm{MHz}\right)$ : d $2.43\left(\mathrm{~s}, 3 \mathrm{H}, \mathrm{CH}_{3} \mathrm{CO}\right), 7.60$ (d, $\left.1 \mathrm{H}, \mathrm{J}=8.5 \mathrm{~Hz}, \mathrm{Ar}-\mathrm{H}_{3}\right), 8.08\left(\mathrm{~d}, 1 \mathrm{H}, \mathrm{J}=8.5 \mathrm{~Hz}, \mathrm{Ar}-\mathrm{H}_{4}\right), 7.79(\mathrm{~d}$, $\left.1 \mathrm{H}, \mathrm{J}=8.8 \mathrm{~Hz}, \mathrm{Ar}-\mathrm{H}_{5}\right), 7.50\left(\mathrm{t}, 1 \mathrm{H}, \mathrm{J}=7.5 \mathrm{~Hz}, \mathrm{Ar}-\mathrm{H}_{6}\right), 7.70\left(\mathrm{t}, 1 \mathrm{H}, \mathrm{J}=7.6 \mathrm{~Hz}, \mathrm{Ar}-\mathrm{H}_{7}\right), 8.13\left(\mathrm{~d}, 1 \mathrm{H}, \mathrm{J}=8.6 \mathrm{~Hz}, \mathrm{Ar}-\mathrm{H}_{8}\right), 7.74$ $\left.\left(\mathrm{d}, 1 \mathrm{H}, \mathrm{J}=16.4 \mathrm{~Hz}, \mathrm{H}_{1}{ }^{\prime}\right), 7.42\left(\mathrm{~d}, 1 \mathrm{H}, \mathrm{J}=16.4 \mathrm{~Hz}, \mathrm{H}_{2}\right)^{\prime}\right), 7.28\left(\mathrm{~d}, 1 \mathrm{H}, \mathrm{J}=9.0 \mathrm{~Hz}, \mathrm{Ar}-\mathrm{H}_{3^{\prime \prime}}\right), 7.81(\mathrm{dt}, 1 \mathrm{H}, \mathrm{J}=8.3 ; 10.2 \mathrm{~Hz}, \mathrm{Ar}-$ $\left.\mathrm{H}_{4^{\prime \prime}}\right), 7.34\left(\mathrm{dt}, 1 \mathrm{H}, \mathrm{J}=6.1 ; 6.8 \mathrm{~Hz}, \mathrm{Ar}-\mathrm{H}_{5^{\prime \prime}}\right), 7.14\left(\mathrm{dd}, 1 \mathrm{H}, \mathrm{J}=7.8 ; 7.9 \mathrm{~Hz}, \mathrm{Ar}-\mathrm{H}_{6}{ }^{\prime \prime}\right),{ }^{13} \mathrm{C}-\mathrm{NMR}\left(\mathrm{CDCl}_{3}\right): \mathrm{d} 21.20\left(\mathrm{CH}_{3} \mathrm{CO}\right)$, 169.37 (C=0), 155.60 (C-2), 119.2 (C-3), 129.40 (C-4), 129.10 (C-4a), 127.53 (C-5), 126.40 (C-6), 129.80 (C-7), 136.50 (C-8), 148.67 (C-8a), 127.71 (C-1'), 131.23 (C-2'), 127.40 (C-1"), 148.12 (C-2"), 126.3 (C-3"), 127.00 (C-4"), 129.47 (C-5"), $122.9(\mathrm{C}-6 ")$.

2-[(E)-2-(8-Hydroxyquinolin-2-yl)ethenyl]phenylacetate (4b) was obtained as a yellow solid at a 71\% yield; ${ }^{1} \mathrm{H}$ NMR $\left(\mathrm{CDCl}_{3}, 300 \mathrm{MHz}\right): \mathrm{d} 2.42\left(\mathrm{~s}, 3 \mathrm{H}, \mathrm{CH}_{3} \mathrm{CO}\right), 7.60\left(\mathrm{~d}, 1 \mathrm{H}, \mathrm{J}=8.5 \mathrm{~Hz}, \mathrm{Ar}-\mathrm{H}_{3}\right), 8.14\left(\mathrm{~d}, 1 \mathrm{H}, \mathrm{J}=8.6 \mathrm{~Hz}, \mathrm{Ar}-\mathrm{H}_{4}\right), 7.79(\mathrm{~d}, 1 \mathrm{H}, \mathrm{J}$ $\left.=7.8 \mathrm{~Hz}, \mathrm{Ar}-\mathrm{H}_{5}\right), 7.39\left(\mathrm{t}, 1 \mathrm{H}, \mathrm{J}=7.5 \mathrm{~Hz}, \mathrm{Ar}-\mathrm{H}_{6}\right), 7.36-7.25\left(\mathrm{~m}, 1 \mathrm{H}, \mathrm{Ar}-\mathrm{H}_{7}\right), 7.75\left(\mathrm{~d}, 1 \mathrm{H}, \mathrm{J}=16.0 \mathrm{~Hz}, \mathrm{H}_{1}\right), 7.42(\mathrm{~d}, 1 \mathrm{H}$, $\left.\mathrm{J}=16.0 \mathrm{~Hz}, \mathrm{H}_{2^{\prime}}\right), 7.36-7.25\left(\mathrm{~m}, 1 \mathrm{H}, \mathrm{Ar}-\mathrm{H}_{3^{\prime \prime}}\right), 7.18\left(\mathrm{dd}, 1 \mathrm{H}, \mathrm{J}=7.5 ; 7.6 \mathrm{~Hz}, \mathrm{Ar}-\mathrm{H}_{4^{\prime \prime}}\right), 7.14(\mathrm{dd}, 1 \mathrm{H}, \mathrm{J}=8.0 ; 7.8 \mathrm{~Hz}, \mathrm{Ar}-$ 
$\left.\mathrm{H}_{5 \prime \prime}\right)$, 7.36-7.25 (m, 1H, $\left.\mathrm{Ar}-\mathrm{H}_{6 "}\right) \cdot{ }^{13} \mathrm{C} \mathrm{NMR}\left(\mathrm{CDCl}_{3}\right)$ : d $21.17\left(\mathrm{CH}_{3} \mathrm{CO}\right), 169.26(\mathrm{C}=0), 153.24(\mathrm{C}-2), 120.49$ (C-3); 136.80 (C-4), 129.03 (C-4a), 127.17 (C-5); 127.80 (C-6), 151.96 (C-8); 148.76 (C-8a), 127.70 (C1'), 127.70 (C2'), 129.03 (C-1"); 151.96 (C-2"), 126.30 (C-3"), 110.47 (C4"); 122.9 (C5").

2-Methoxy-6-[(E)-2-(quinolin-2-yl)ethenyl]phenylacetate (4c) was obtained as a white solid with a yield of $87 \%$; ${ }^{1} \mathrm{H}$ NMR $\left(\mathrm{CDCl}_{3}, 300 \mathrm{MHz}\right): \mathrm{d} 2.46\left(\mathrm{~s}, \mathrm{CH}_{3} \mathrm{CO}\right), 3.87\left(\mathrm{~s}, \mathrm{OCH}_{3}\right), 7.67\left(\mathrm{~d}, 1 \mathrm{H}, \mathrm{J}=8.6 \mathrm{~Hz}, \mathrm{Ar}-\mathrm{H}_{3}\right), 8.15\left(\mathrm{~d}, 1 \mathrm{H}, \mathrm{J}=8.6 \mathrm{~Hz}, \mathrm{Ar}-\mathrm{H}_{4}\right)$, $7.80\left(\mathrm{~d}, 1 \mathrm{H}, \mathrm{J}=8.1 \mathrm{~Hz}, \mathrm{Ar}-\mathrm{H}_{5}\right), 7.52\left(\mathrm{t}, 1 \mathrm{H}, \mathrm{J}=7.4 \mathrm{~Hz}, \mathrm{Ar}-\mathrm{H}_{6}\right), 7.72\left(\mathrm{~d}, 1 \mathrm{H}, \mathrm{J}=6.2 \mathrm{~Hz}, \mathrm{Ar}-\mathrm{H}_{7}\right), 8.10(\mathrm{~d}, 1 \mathrm{H}, \mathrm{J}=8.6$ $\left.\left.\mathrm{Hz}, \mathrm{Ar}-\mathrm{H}_{8}\right), 7.74\left(\mathrm{~d}, 1 \mathrm{H}, \mathrm{J}=16.5 \mathrm{~Hz}, \mathrm{H}_{1^{\prime}}\right), 7.43\left(\mathrm{~d}, 1 \mathrm{H}, \mathrm{J}=16.4 \mathrm{~Hz}, \mathrm{H}_{2}\right)^{\prime}\right), 6.96\left(\mathrm{~d}, 1 \mathrm{H}, \mathrm{J}=7.9 \mathrm{~Hz}, \mathrm{Ar}-\mathrm{H}_{4^{\prime \prime}}\right), 7.26(\mathrm{t}, 1 \mathrm{H}, \mathrm{J}=$ $\left.7.9 \mathrm{~Hz}, \mathrm{Ar}-\mathrm{H}_{5^{\prime \prime}}\right), 7.43\left(\mathrm{~d}, 1 \mathrm{H}, \mathrm{J}=8.0 \mathrm{~Hz}, \mathrm{Ar}-\mathrm{H}_{6^{\prime \prime}}\right) .{ }^{13} \mathrm{C} \mathrm{NMR}\left(\mathrm{CDCl}_{3}, 75 \mathrm{MHz}\right): \mathrm{d}(\mathrm{ppm}) 20.60\left(\mathrm{CH}_{3} \mathrm{CO}\right), 56.02\left(\mathrm{OCH}_{3}\right)$, 168.45 (C=0), 155.64 (C-2), 119.27 (C-3), 136.33 (C-4), 127.41 (C-4a), 127.54 (C-5), 126.31 (C-6), 129.65 (C-7), 129.29 (C-8), 148.15 (C-8a), 127.36 (C-1'), 131.58 (C-2'), 130.38 (C-1"), 138.17 (C-2"), 151.45 (C-3"), 112.07 (C-4"), 126.48 (C5"), $118.22(\mathrm{C}-6 ")$.

2-Methoxy-6-[(E)-2-(8-hydroxyquinolin-2-yl)ethenyl]phenylacetate (4d) was obtained as a white solid with a yield of $90 \% ;{ }^{1} \mathrm{H} \mathrm{NMR}\left(\mathrm{CDCl}_{3}, 300 \mathrm{MHz}\right)$ : d 2.48 (s, 3H, $\left.\mathrm{CH}_{3} \mathrm{CO}\right), 3.90\left(\mathrm{~s}, 3 \mathrm{H}, \mathrm{OCH}_{3}\right), 7.64\left(\mathrm{~d}, 1 \mathrm{H}, \mathrm{J}=8.6 \mathrm{~Hz}, \mathrm{Ar}-\mathrm{H}_{3}\right), 8.15(\mathrm{~d}, 1 \mathrm{H}, \mathrm{J}$ $\left.=8.6 \mathrm{~Hz}, \mathrm{Ar}-\mathrm{H}_{4}\right), 7.33\left(\mathrm{~d}, 1 \mathrm{H}, \mathrm{J}=8.3 \mathrm{~Hz}, \mathrm{Ar}-\mathrm{H}_{5}\right), 7.23\left(\mathrm{dd}, 1 \mathrm{H}, \mathrm{J}=8.3 ; 7.5 \mathrm{~Hz}, \mathrm{Ar}-\mathrm{H}_{6}\right), 7.47(\mathrm{~d}, 1 \mathrm{H}, \mathrm{J}=8.0 \mathrm{~Hz}, \mathrm{Ar}-$ $\left.\mathrm{H}_{7}\right), 7.77\left(\mathrm{~d}, 1 \mathrm{H}, \mathrm{J}=16.5 \mathrm{~Hz}, \mathrm{H}_{1^{\prime}}\right), 7.38\left(\mathrm{~d}, 1 \mathrm{H}, \mathrm{J}=16.5 \mathrm{~Hz}, \mathrm{H}_{2^{\prime}}\right), 7.45\left(\mathrm{~d}, 1 \mathrm{H}, \mathrm{J}=8.0 \mathrm{~Hz}, \mathrm{Ar}-\mathrm{H}_{4^{\prime \prime}}\right), 7.28(\mathrm{t}, 1 \mathrm{H}, \mathrm{J}=8.0 \mathrm{~Hz}$, $\left.\mathrm{Ar}-\mathrm{H}_{5^{\prime \prime}}\right), 6.99\left(\mathrm{~d}, 1 \mathrm{H}, \mathrm{J}=8.0 \mathrm{~Hz}, \mathrm{Ar}-\mathrm{H}_{6^{\prime \prime}}\right) .{ }^{13} \mathrm{C} \mathrm{NMR}\left(\mathrm{CDCl}_{3}\right): \mathrm{d} 20.32\left(\mathrm{CH}_{3} \mathrm{CO}\right), 56.18\left(\mathrm{OCH}_{3}\right), 168.87(\mathrm{C}=0), 153.23(\mathrm{C}-$ 2), 120.35 (C-3), 136.52 (C-4), 130.22 (C-4a), 117.54 (C-5), 110.15 (C-6), 127.38 (C-7), 138.18 (C-8), 151.96 (C-8a), 127.38 (C-1'), 130.72 (C-2'), 127.49 (C-1"), 151.47 (C-2"), 151.47 (C-3"), 118.41 (C-4"), 126.68 (C-5"), 111.90 (C-6").

4-Bromo-2-[(E)-2-(quinolin-2-yl)ethenyl]phenylacetate (4e) was obtained as white crystals at a yield of $90 \%$; ${ }^{1} \mathrm{H}$ - $\mathrm{NMR}$ $\left(\mathrm{CDCl}_{3}, 300 \mathrm{MHz}\right): \mathrm{d} 2.34\left(\mathrm{~s}, 3 \mathrm{H}, \mathrm{CH}_{3} \mathrm{CO}\right), 7,63\left(\mathrm{~d}, 1 \mathrm{H}, \mathrm{J}=8.8 \mathrm{~Hz}, \mathrm{Ar}-\mathrm{H}_{3}\right), 8.01\left(\mathrm{~d}, 1 \mathrm{H}, \mathrm{J}=9,4 \mathrm{~Hz}, \mathrm{Ar}-\mathrm{H}_{4}\right), 7.71(\mathrm{~d}, 1 \mathrm{H}, \mathrm{J}$ $\left.=8.0 \mathrm{~Hz}, \mathrm{Ar}-\mathrm{H}_{5}\right), 7.45\left(\mathrm{t}, 1 \mathrm{H}, \mathrm{J}=7.1 \mathrm{~Hz}, \mathrm{Ar}-\mathrm{H}_{6}\right), 7.50\left(\mathrm{~d}, 1 \mathrm{H}, \mathrm{J}=8,5 \mathrm{~Hz}, \mathrm{Ar}-\mathrm{H}_{7}\right), 8.04\left(\mathrm{~d}, 1 \mathrm{H}, \mathrm{J}=8.9 \mathrm{~Hz}, \mathrm{Ar}-\mathrm{H}_{8}\right)$, $7.60\left(\mathrm{~d}, 1 \mathrm{H}, \mathrm{J}=16.3 \mathrm{~Hz}, \mathrm{H}_{1}\right), 7.28\left(\mathrm{~d}, 1 \mathrm{H}, \mathrm{J}=16.3 \mathrm{~Hz}, \mathrm{H}_{2^{\prime}}\right), 6,94\left(\mathrm{~d}, 1 \mathrm{H}, \mathrm{J}=8,6 \mathrm{~Hz}, \mathrm{Ar}-\mathrm{H}_{3^{\prime \prime}}\right), 7.36(\mathrm{~d}, 1 \mathrm{H}, \mathrm{J}=8.6 \mathrm{~Hz}, \mathrm{Ar}-$ $\left.\mathrm{H}_{4 \prime \prime}\right), 7,86\left(\mathrm{~s}, 1 \mathrm{H}, \mathrm{Ar}-\mathrm{H}_{6}\right)^{13} \mathrm{C}-\mathrm{NMR}\left(\mathrm{CDCl}_{3}\right)$ : d $20.94\left(\mathrm{CH}_{3} \mathrm{CO}\right), 168.92$ (C=0), 154.92 (C-2), 129.35 (C-3), 129.35 (C-4), 129.67 (C-4a), 127.46 (C-5), 126.40 (C-6), 119.53 (C-7), 136.43 (C-8), 148.17 (C-8a), 125.95 (C-1'), 132.17 (C-2'), 119.48 $\left(\mathrm{C}-1^{\prime \prime}\right), 131.19$ (C-2"), 124.54 (C-3"), 131.94 (C-4"), 147.53 (C-5"), 129.68 (C-6").

2-Ethoxy-4-[(E)-2-(quinolin-2-yl)ethenyl]phenylacetate (4f) was obtained as white crystals with a yield of $739.4 \mathrm{mg}$ (37\%); ${ }^{1} \mathrm{H}-\mathrm{NMR}\left(\mathrm{CDCl}_{3}, 300 \mathrm{MHz}\right): \mathrm{d} 4,14$ (q, $\left.2 \mathrm{H}, \mathrm{J}=6,9 \mathrm{~Hz}, \mathrm{OCH}_{2} \mathrm{CH}_{3}\right), 1,42\left(\mathrm{t}, 3 \mathrm{H}, \mathrm{J}=6,9 \mathrm{~Hz}, \mathrm{OCH}_{2} \mathrm{CH}_{3}\right), 2,32(\mathrm{~s}$, $3 \mathrm{H}, \mathrm{CH}_{3} \mathrm{CO}$ ), $7.69\left(\mathrm{~d}, 1 \mathrm{H}, \mathrm{J}=9.0 \mathrm{~Hz}, \mathrm{Ar}-\mathrm{H}_{3}\right), 8.07\left(\mathrm{~d}, 1 \mathrm{H}, \mathrm{J}=9.0 \mathrm{~Hz}, \mathrm{Ar}-\mathrm{H}_{4}\right), 7.77\left(\mathrm{~d}, 1 \mathrm{H}, \mathrm{J}=8.1 \mathrm{~Hz}, \mathrm{Ar}-\mathrm{H}_{5}\right), 7.48(\mathrm{t}$, $\left.1 \mathrm{H}, \mathrm{J}=7.5 \mathrm{~Hz}, \mathrm{Ar}-\mathrm{H}_{6}\right), 7.70\left(\mathrm{t}, 1 \mathrm{H}, \mathrm{J}=8.6 \mathrm{~Hz}, \mathrm{Ar}-\mathrm{H}_{7}\right), 8.11\left(\mathrm{~d}, 1 \mathrm{H}, \mathrm{J}=9.0 \mathrm{~Hz}, \mathrm{Ar}-\mathrm{H}_{8}\right), 7.60\left(\mathrm{~d}, 1 \mathrm{H}, \mathrm{J}=16.0 \mathrm{~Hz}, \mathrm{H}_{1}\right)$, $7.36\left(\mathrm{~d}, 1 \mathrm{H}, \mathrm{J}=16.0 \mathrm{~Hz}, \mathrm{H}_{2^{\prime}}\right), 7.25\left(\mathrm{~s}, 1 \mathrm{H}, \mathrm{Ar}-\mathrm{H}_{2^{\prime \prime}}\right), 7.17\left(\mathrm{~d}, 1 \mathrm{H}, \mathrm{J}=8.2 \mathrm{~Hz}, \mathrm{Ar}-\mathrm{H}_{5^{\prime \prime}}\right), 7.05\left(\mathrm{~d}, 1 \mathrm{H}, \mathrm{J}=8.2 \mathrm{~Hz}, \mathrm{Ar}-\mathrm{H}_{6^{\prime \prime}}\right)$

${ }^{13} \mathrm{C}$ - NMR $\left(\mathrm{CDCl}_{3}\right)$ : d $64.33\left(\mathrm{CH}_{2}\right), 14,71\left(\mathrm{CH}_{3}\right), 20.56\left(\mathrm{CH}_{3} \mathrm{CO}\right), 168.93(\mathrm{C}=0), 155.75(\mathrm{C}-2), 119.08(\mathrm{C}-3), 129.10(\mathrm{C}-4)$, 140.45 (C-4a), 127.51 (C-5), 126.28 (C-6), 129.80 (C-7), 136.48 (C-8), 150.63 (C-8a), 133,84 (C-1'), 129,10 (C-2'), 135,38 $\left(\mathrm{C}-1^{\prime \prime}\right), 111.34$ (C-2"), 148,45 (C-3"), 140.45 (C-4"), 120.48 (C-5"), 122.94 (C-6").

\section{Biological Activity Assays}

Compounds. The compounds were solubilized in 0.5\% dimethyl sulfoxide (DMSO; Sigma-Aldrich, St Louis MO, USA) and a $100 \mu \mathrm{g} / \mathrm{mL}$ solution was prepared in RPMI-1640 medium (Gibco, Thermo Scientific Inc., Waltham, MA, USA). Then, four serial quadruple dilutions equivalent to $100,25,6.25$, and $1.625 \mu \mathrm{g} / \mathrm{mL}$ were prepared. For amphotericin $B$, which was used as a control drug, four solutions were prepared from $1.0 \mu \mathrm{g} / \mathrm{mL}$. 
Parasite. The L. (V) panamensis strain M / HOM / 87 / UA140 was used, transfected with the gene for green fluorescent protein (UA140-EGFP) generated in a previous work ${ }^{54}$. Parasites were cultured as promastigotes in NovyMacNeil-Nicolle (NNN) biphasic medium and phosphate buffered saline (PBS) with glucose (pH 6.9) as the liquid phase. The cultures were incubated at $26^{\circ} \mathrm{C}$. To ensure a greater infection of macrophages in vitro, the $L$. (V) panamensis strain was maintained by successive passages in experimentally infected hamsters (Mesocricetus auratus), making periodic aspirations of hamster lesions using PBS and \#26 needles. The aspirated samples were grown in NNN culture medium at $26^{\circ} \mathrm{C}$, until promastigotes were obtained, which were used to infect U937 macrophages as described below ${ }^{54-57}$.

Cells. Human monocytes of the U-937 line (ATCC-CRL-1593-2TM) were kept cultured in suspension in complete RPMI1640 medium -that is, supplemented with 10\% fetal bovine serum (FBS; Invitrogen) and a 1\% mixture of antibiotics composed of penicillin $(10,000 \mathrm{U} / \mathrm{mL})$ and streptomycin $\left(10,000 \mathrm{U} / \mathrm{mL}\right.$; Sigma) -and incubated at $37^{\circ} \mathrm{C}$ with $5 \% \mathrm{CO}_{2}$ 54.

Cytotoxicity in U-937 macrophages. Cytotoxicity was evaluated in U-937 cells using the enzymatic micromethod with 3- (4,5-dimethylthiazol-2-yl)-2,5-diphenyltetrazolium (MTT) bromide (Sigma). Cells in exponential phase of growth were adjusted to a concentration of 100,000 cells/mL of complete RPMI-1640 medium. In each well of a 96-well cell culture dish (Falcon, Fisher Scientific, Thermo Scientific Inc., Waltham, MA, USA), $100 \mu \mathrm{L}$ of cells were deposited. Then, $100 \mu \mathrm{L}$ of each of the corresponding concentrations of each compound $(200,50,12.5$, or $3.125 \mu \mathrm{g} / \mathrm{mL}) \mathrm{was}$ added to each well. As a viability control (no cytotoxicity), cells incubated in complete RPMI-1640 medium were used, while cells exposed to doxorubicin (DOX) were used as a cytotoxicity control ${ }^{54}$.

Cytotoxicity was determined according to the percentage decrease in the number of living cells obtained for each concentration of compound or amphotericin B (AMB), according to the optical densities (OD) obtained in each experimental condition and, in comparison, with the OD obtained from cells not exposed to any compound. The decrease in cell viability (called inhibition of cell growth) was calculated using the OD values for each evaluated condition, through the following equation: \% Viability $=[O D$ cells exposed to the compound $\div$ OD cells not exposed] $x$ 100. The OD values obtained for cells in the absence of compounds corresponded to $100 \%$ viability 54,55 .

The cells in the presence of the different solutions of the compounds at the respective concentrations, as well as the cells exposed to amphotericin $\mathrm{B}$ and doxorubicin and those not exposed, were incubated at $37^{\circ} \mathrm{C}$ in a $5 \% \mathrm{CO}_{2}$ atmosphere for 72 hours. After the incubation period, $10 \mu \mathrm{L} /$ well of a MTT solution with a concentration of $5 \mu \mathrm{g} / \mathrm{mL}$ (Sigma) was added and the dishes were incubated at $37^{\circ} \mathrm{C}$ for 3 hours. After this incubation period, $100 \mu \mathrm{L} /$ well of a solution of $50 \%$ isopropanol (Merck Millipore) and $10 \%$ sodium dodecyl sulfate (SDS) (Merck Millipore) was added, in order to solubilize the formazan crystals formed. The plates were incubated for another 30 minutes and the production of formazan (which is proportional to the percentage of viable cells) was measured in a microplate reader (Benchmark Bio-Rad Hercules, CA, USA) at a wavelength of $570 \mathrm{~nm}^{54}$.

From the percentage of viability, the percentage of mortality was calculated, which corresponds to the reciprocal of viability. Finally, with the mortality percentages, the mean lethal concentration $\left(\mathrm{LC}_{50}\right)$ was calculated, using the dose response analysis method Probit with the SAS Data Analysis statistical program (SAS Institute Cary NC, USA). The tests were carried out twice, with three replicates for each concentration evaluated. The cytotoxicity of each compound was classified, according to the $\mathrm{LC}_{50}$ values, using the following scale: high cytotoxicity, $\mathrm{LC}_{50}<100 \mu \mathrm{g} / \mathrm{mL}$; moderate cytotoxicity, $100<\mathrm{LC}_{50}<200 \mu \mathrm{g} / \mathrm{mL}$; and low cytotoxicity, $\mathrm{LC}_{50}>200 \mu \mathrm{g} / \mathrm{mL}^{54}$. 
In vitro antileishmanial activity of compounds $4 \mathrm{a}-\mathrm{f}$. The activity of the compounds was evaluated in intracellular amastigotes obtained after in vitro infection of macrophages U-937. For this, the U-937 cells maintained in suspension culture were centrifuged at 1,500 rpm for 10 minutes and, after discarding the supernatant, the button cells were resuspended at a concentration of $1 \times 10^{5}$ cells $/ \mathrm{mL}$ of complete RPMl 1640 medium and $0.1 \mu \mathrm{g} / \mathrm{mL} \mathrm{phorbol}$ myristate acetate (PMA; Sigma). In each well of a 24-well cell culture plate (Falcon), $1 \mathrm{~mL}$ of the cell suspension was dispersed and incubated at a temperature of $37^{\circ} \mathrm{C}$ with a $5 \% \mathrm{CO}_{2}$ atmosphere. After 72 hours, cells were infected with promastigotes in stationary phase of growth at a ratio of $15: 1$ parasites/cell. The dishes were incubated at $34{ }^{\circ} \mathrm{C}$ under $5 \% \mathrm{CO}_{2}$ for 2 hours. Subsequently, two washes with PBS were carried out to eliminate free parasites, $1 \mathrm{~mL}$ of complete RPMI 1640 medium was added, and the cells were incubated again for 24 hours. After this, the infected cells were exposed to each of the concentrations of the compounds for 72 hours. As infection control, infected and cultured cells were used in the absence of the compounds and amphotericin B was used as a control of antileishmanial activity. After 72 hours of incubation at $34{ }^{\circ} \mathrm{C}$ and $5 \% \mathrm{CO}_{2}$, the cells were carefully removed from the bottom of the plate using the plunger of a syringe and analysed in an Argon laser flow cytometer, reading at $488 \mathrm{~nm}$ excitation and $525 \mathrm{~nm}$ emission (Beckman-Coulter Cytomics ${ }^{\mathrm{tm}}$ MCL FC 500 Brea, CA, USA). Each concentration of the compounds, including amphotericin $B$, was evaluated in triplicate in two different experiments. The antileishmanial activity was determined according to the number of parasites in the infected cells obtained for each concentration of each compound and for amphotericin B, according to the number of positive events for green fluorescence using dot diagrams, as well as according to the average intensity of fluorescence (IFM) using histograms ${ }^{55}$.

The inhibition of infection-that is, the decrease in the number of parasites due to the effect of the evaluated compounds - was calculated using the following equation: \% Infection $=$ [MFI infected and exposed cells $\div \mathrm{MFI}$ infected and unexposed cells] $\times 100$, where the IFM values obtained for infected cells in the absence of compounds corresponded to $100 \%$ infection. In turn, the percentage of infection inhibition corresponded to the reciprocal of the infection. With the \% inhibition of the infection, the mean Effective Concentration $\left(\mathrm{EC}_{50}\right)$ calculated by the Probit method ${ }^{26}$ was determined, which corresponds to the maximum concentration that reduces $50 \%$ of infection. As for cytotoxicity, antileishmanial activity was classified, according to the $\mathrm{EC}_{50}$ values, as follows: high activity, $\mathrm{EC}_{50}<25$ $\mu \mathrm{g} / \mathrm{mL}$; moderate activity, $25<\mathrm{EC}_{50}<50 \mu \mathrm{g} / \mathrm{mL}$; and low activity, $\mathrm{EC}_{50}>50 \mu \mathrm{g} / \mathrm{mL}$. Finally, the cytotoxic activity was correlated with the antileishmanial activity by calculating the Selectivity Index (IS), using the following equation: IS = $\mathrm{LC}_{50} \div \mathrm{EC}_{50} 26,27$.

In vivo therapeutic response of a cream formulation of compounds $4 a-f$. Juvenile hamsters of both sexes were injected intradermally with $1 \times 10^{8}$ stationary growth phase promastigotes of $L$. (V) panamensis in $100 \mu \mathrm{L}$ phosphate buffer saline (PBS), in the dorsum. After development of an ulcer, hamsters were distributed into four experimental groups ( $n=5$ each). Three groups of hamsters were treated with topical administration of $40 \mathrm{mg} / \mathrm{day}$ of $1 \% 4 \mathrm{a}, 4 \mathrm{~b}, \mathbf{4 c}$, $\mathbf{4 d}, \mathbf{4 e}$, and $\mathbf{4 f}$, for 20 days. The fourth group of hamsters was treated with intralesional meglumine antimoniate (MA; $200 \mu \mathrm{g}$ ) administered twice per week for 3 weeks. Animal welfare was supervised daily during the study. The size of the lesion was measured at the end of treatment (TD20), as well as at days 30,60, and 90 post-treatment, denoted by PTD30, PTD60, and PTD90, respectively $57,27,28$. During these time points, hamsters were weighed and supervised for changes in behaviour, water, and food consumption, as well as the appearance of urine and faeces. In vivo methods used in this research were reviewed and approved by Universidad de Antioquia's Ethics Committee for Animal Experimentation in Act $\mathrm{N}^{\circ} 131$ of February 11, 2020. Euthanasia of hamster specimens was carried out by sodium pentobarbital overdose. Euthanasia, sample collection and handling of the animals was done in compliance of Center for Diseases Control and Prevention guidelines for Safe Work Practices in Human and Animal Medical Diagnostic Laboratories and ARRIVE guidelines ${ }^{58,59}$. 
The effectiveness of each treatment was determined after comparing the lesion sizes prior to and after treatments. Treatment outcome at the end of study was recorded as cure (healing of $100 \%$ of the area and complete disappearance of the lesion), improvement (any percentage of reduction of lesion), failure (low decrease or an increase in the size of the lesion), or relapse (reactivation of lesion after initial cure). Toxicity of the cream formulations was determined according to changes in the body weight obtained during and after treatment, as well as the levels of alanine amino transferase (ALT), blood urea nitrogen (BUN), and creatinine metabolites in serum before treatment (TDO) and at day 8 of treatment (TD8) ${ }^{60}$.

Statistical analysis. Values are expressed as mean \pm SD. Data were analysed by two-way ANOVA. Differences were considered significant if $P<0.05$. Statistical analysis was performed with the Prism 6.0 software (Graph pad Prism, San Diego, CA, USA).

Molecular Docking and Ligand Efficiency Approach. Molecular docking analyses were performed to study the possible binding modes of $\mathbf{4 a - f}$ to $L$. major dihydroorotate dehydrogenase ( $L \mathrm{mDHODH}){ }^{45,47}$ and L. majortryparedoxin peroxidase I ( $L m T X N P x)^{61}$, as potential inhibitors, as there have been interesting studies of molecular docking of quinoline derivatives, including studies of leishmanicidal activity ${ }^{62}$. Based on the binding energy landscapes, compounds with the most negative scores, and previously published data ${ }^{48}$, these two crystals from $L$. major were prioritized for in vitro validation. The binding sites of $L m D H O D H$ and $L m T X N P x$ inhibitors have been characterized, based on structural information derived from the position of the ligand for proteins co-crystallized with a bound ligand. Literature data ${ }^{47,48,61,63}$ were used to determine active site residues for these structures. AutoDock (v 4.2.1) and AutoDock Vina ( $v$ 1.0.2) ${ }^{64}$ were used for all dockings in this study. The three-dimensional coordinates of structures $4 \mathbf{a}-\mathbf{f}$ structures were obtained from the PubChem database and energy optimized using the MOPAC2016 ${ }^{65}$ software, through the PM6-D3H4 semi-empirical method ${ }^{66,67}$. When ligand structures were not available from PubChem, they were drawn using Discovery Studio ${ }^{68} 3.1$ (Accelrys, CA). The ligand files were prepared using the AutoDockTools package ${ }^{69}$, provided by AutoDock, accepting all rotatable bonds. The partial charges of each ligand were determined using the PM6-D3H4 semi-empirical method; this approach introduces dispersion and hydrogen-bonded corrections to the PM6 method. The crystal structures of LmDHODH (PDB Code: 3MJY) and $L m T X N P x$ (PDB Code: 4K1F) were downloaded from the Protein Data Bank ${ }^{70}$. LmDHODH and $L m T X N P$ were treated with Schrödinger's Protein Preparation Wizard ${ }^{71}$; polar hydrogen atoms were added, non-polar hydrogen atoms were merged, and charges were assigned. Docking was treated as rigid and carried out using the empirical free energy function and the Lamarckian Genetic Algorithm provided by AutoDock Vina ${ }^{72}$. The grid map dimensions were $20 \times 20$ x $20 \AA^{3}$, with $0.375 \AA$ spacing between grid points, making the binding pocket of $L m D H O D H$ the centre of the flavin mononucleotide cofactor and S2 subsite catalytic residues (Ser100, Asn128, Gln139, Val140), while the active site of $L m T X N P$ was defined as the centre of Arg128. All other parameters were set as the defaults defined by AutoDock Vina. Dockings were repeated 20 times, with the space search exhaustiveness set to 20.

The best interaction binding energy $\left(\mathrm{kcal} \cdot \mathrm{mol}^{-1}\right)$ was selected for evaluation. Docking result 3D representations were used, from the Discovery Studio ${ }^{68}$ molecular graphics system. In this context, and based on our past experience ${ }^{73}$, we demonstrated that, in $L m D H O D H$, the S2 sub-site is essential for the activity of the $L m D H O D H$ enzyme, which contains active amino acids within the loop (a4-bA) ${ }^{45,47}$. In the case of LmTXNPX (PDB Code: 3TUE), catalyse TS2-dependent peroxide detoxification. These types of mechanisms are useful for the design of new drugs, as they are unique to the parasite and necessary for its survival ${ }^{63}$.The active site was visualized through PDB Code: 4K1F. 
Ligand efficiency (LE) calculations were performed using one parameter, $\mathrm{K}_{\mathrm{d}}$. The $\mathrm{K}_{\mathrm{d}}$ parameter corresponds to the dissociation constant between a ligand/protein, and its value indicates the bond strength between the ligand/protein ${ }^{74-76} \cdot \mathrm{K}_{\mathrm{d}}$ calculations were carried out using the following equations:

$$
\begin{aligned}
& \Delta G^{0}=-2.303 R T \log \left(K_{d}\right), \\
& K_{d}=10 \frac{\Delta G^{0}}{2.303 R T},
\end{aligned}
$$

where $\Delta G^{0}$ is the binding energy $\left(\mathrm{kcal} \cdot \mathrm{mol}^{-1}\right)$ obtained from docking experiments, $R$ is the gas constant, and $T$ is the temperature (in Kelvin). We considered standard conditions of aqueous solution at $298.15 \mathrm{~K}$, neutral pH, and remaining concentrations of $1 \mathrm{M}$. The LE allows us to compare molecules, according to their average binding energy ${ }^{77,78}$. Thus, it is determined as the ratio of binding energy per non-hydrogen atom, as follows ${ }^{78-81}$ :

$$
L E=-\frac{2.303 R T}{H A C} \log \left(K_{d}\right)
$$

where $\mathrm{K}_{\mathrm{d}}$ is obtained from Equation 2 and $\mathrm{HAC}$ denotes the heavy atom count (i.e., the number of non-hydrogen atoms) in a ligand. The obtained results are shown in Tables 4-6 and Figures S4 and S5.

\section{Results And Discussion}

Compounds 4a-f, were obtained using acetic anhydride and high temperatures as a reaction condition, with yields between $37-90 \%$. The synthesis strategy was based on the modification of the aromatic aldehyde and the quinolinic ring, to determine the change in biological activity of the compounds (Figure 1$)^{25}$.

\section{Biological activities}

The results of in vitro cytotoxic and Leishmanicidal activity are summarized in Table 1. All compounds $4 a-f$ were shown to be cytotoxic to U-937 cells. As expected, Amphotericin B (AMB) and Doxorubicin (DOX) showed high cytotoxicity, with $\mathrm{LC}_{50}$ values of $0.05 \mu \mathrm{M}$ and $0.02 \mu \mathrm{M}$, respectively. Despite the high cytotoxicity, all compounds $4 a-f$ were also active against intracellular amastigotes of L. (V) panamensis, with inhibition percentages greater than $50 \%$ (Table 1). The most active compounds were $\mathbf{4 c}$, inhibiting $91.2 \%$, followed by $\mathbf{4 d}$ and $\mathbf{4 c}$, with inhibition of $88.4 \%$ and $87.8 \%$, respectively. AMB, used as a control compound for antileishmanial activity, showed a percentage of inhibition of $69 \%$ (Table 1).

The dose-response relationship showed that all compounds $\mathbf{4 a - f}$ are highly active against intracellular amastigotes of $L$. ( $V$ ) panamensis, with compound $\mathbf{4 b}$ being the most active, with an $\mathrm{EC}_{50}$ of $3.8 \mu \mathrm{M}$, followed by $\mathbf{4 a}$ and $\mathbf{4} \mathbf{c}$, with $\mathrm{EC}_{50}$ of $5.1 \mu \mathrm{M}$ and $4.9 \mu \mathrm{M}$, respectively, showing values very close to that of the control drug (AMB), which showed activity with $\mathrm{EC}_{50}$ values of $0.005 \mu \mathrm{M}$ (Table 1 ).

Table 1. Results of in vitro leishmanicidal activity and cytotoxicity of synthesized compounds. 


\begin{tabular}{|c|c|c|c|c|c|c|}
\hline \multirow[t]{3}{*}{ Compounds } & \multicolumn{6}{|c|}{ Intracellular Amastigotes } \\
\hline & \multicolumn{2}{|c|}{$\mathrm{CL}_{50}^{\mathrm{a}}(\mathrm{U} 937)$} & \multirow[t]{2}{*}{$\%$ of inhibition } & \multicolumn{2}{|l|}{$C E_{50}{ }^{b}$} & \multirow[t]{2}{*}{ IS ${ }^{c}$} \\
\hline & $\mu \mathrm{g} / \mathrm{mL}$ & $\mu \mathrm{M}$ & & $\mu \mathrm{g} / \mathrm{mL}$ & $\mu \mathrm{M}$ & \\
\hline $4 a$ & $8.9 \pm 1.8$ & 30.8 & $91.2 \pm 0.1$ & $1.5+0.4$ & 5,1 & 5.9 \\
\hline $4 b$ & $16.7 \pm 3.8$ & 57.4 & $68.1 \pm 8.2$ & $1.1 \pm 0.1$ & 3.8 & 15.2 \\
\hline $4 c$ & $9.2 \pm 1.9$ & 30.2 & $87.8 \pm 1.4$ & $1.5 \pm 0.3$ & 4.9 & 6.1 \\
\hline $4 d$ & $16.3 \pm 3.5$ & 50.6 & $88.4 \pm 0.7$ & $2.4 \pm 0.1$ & 7.5 & 6.8 \\
\hline $4 e$ & $25.3 \pm 2.7$ & 68.7 & $77.6 \pm 6.4$ & $7.1+0.6$ & 19,3 & 3.6 \\
\hline $4 f$ & $18.4 \pm 0.8$ & 55.2 & $84.7 \pm 4.6$ & $2.8+0.2$ & 8.4 & 6.6 \\
\hline Anfotericina B & $45.4 \pm 7.8$ & 0.05 & $69.1 \pm 1.3^{d}$ & $0.05 \pm 0.01$ & 0.005 & 908 \\
\hline Doxorubicin & $1.2 \pm 0.07$ & 0.02 & NA & NA & NA & NA \\
\hline
\end{tabular}

The results are reported as mean values \pm standard deviation. ${ }^{\mathrm{a}} \mathrm{LC}_{50}$ : Median Lethal concentration; ${ }^{\mathrm{b}} \mathrm{EC} 50$ : Median effective concentration; ${ }^{c}$ Selectivity index $(\mathrm{IS})=\mathrm{LC}_{50} / \mathrm{EC}_{50}{ }^{\mathrm{d}}$ Percentage of inhibition at a concentration of $1 \mu \mathrm{g} / \mathrm{mL}$; NA: not applicable

Although toxicity is an important criterion in the development of new drugs, the criterion of specific biological activity is even more important-in this case, antileishmanial activity-as cytotoxicity can be controlled or reduced by applying drug delivery systems, such as liposomes, and other types of nanoparticles that improve pharmacological activity, without loss of pharmacological potential. For example, AMB is a drug in current use for the treatment of cutaneous and visceral leishmaniasis which, in its free form-amphotericin B deoxycholate-is associated with high renal toxicity, such that treatment must be administered in hospitalized patients. In contrast, if amphotericin B is in a colloidal dispersion, lipid complexes, and liposomes, it has fewer adverse effects and lower renal toxicity 26,27 .

\section{In vivo therapeutic response of the topical formulation of compounds $4 a-f$}

The evolution of ulcers was monitored for 90 days after the end of the treatment. When the treatment was effective, the ulcerative lesions gradually regressed to complete healing $\left(0.0 \mathrm{~mm}^{2}\right)$ or reduced in size. On the contrary, when the treatment did not work, the size of the lesion increased. Treatment with $1 \%$ cream containing compound $\mathbf{4} \mathbf{d}$ was the most effective, managing to cure of $40 \%$ of hamsters and producing improvement in the remaining of $60 \%$ the hamsters in the group (Table 2). For their part, $1 \%$ creams containing compounds $4 \mathbf{b}$ or $\mathbf{4 c}$ managed to cure 0 f $20 \%$ hamsters in each group and produced improvements in the $80 \%$ hamsters, while treatment with compound $\mathbf{4 f}$ cured $20 \%$ hamsters and failed in the remaining in the $80 \%$ hamsters. On the other hand, creams containing compounds $4 a$ or $4 \mathbf{e}$ produced improvement in the $80 \%$ hamsters and failures in the remaining hamster. As expected, MA treatment produced the highest percentage of cures, with thr80\% of the hamsters cured (Table 2)

Table 2. Effectiveness of treatment with compounds $4 a-f$. 


\begin{tabular}{|llll|}
\hline & \multicolumn{3}{l}{ Result $^{\mathrm{a}} \boldsymbol{n}(\%)$} \\
Treatment $^{b}$ & Cure & Improvement & Failure \\
\hline $\mathbf{4 a}^{c}$ & $0(0)$ & $4(80)$ & $1(20)$ \\
\hline 4b & $1(20)$ & $4(60)$ & $0(0)$ \\
\hline 4c & $1(20)$ & $4(60)$ & $0(0)$ \\
\hline 4d & $2(40)$ & $3(60)$ & $0(0)$ \\
\hline 4e & $0(0)$ & $4(80)$ & $1(20)$ \\
\hline 4f & $1(20)$ & $0(0)$ & $4(80)$ \\
\hline MA $^{d}$ & $4(80)$ & $1(20)$ & $0(0)$ \\
\hline
\end{tabular}

The data represent the number and percentages of hamsters, according to the result at the end of the study. ${ }^{a}$ At 3 months after the end of treatment. ${ }^{b} n=5$ animals per group. ${ }^{c}$ Via topical (40 mg) once/day/20 days. ${ }^{d}$ MA: meglumine antimoniate via IL $(200 \mu \mathrm{g})$ twice/week/3 weeks. cure, 100\% healing of the area and complete disappearance of the lesion; improvement, percentage of reduction around the lesion greater than $20 \%$; failure, less than $20 \%$ of reduction of the area of lesion, or any increase in the size of the lesion.

The percentages of reduction (in positive values) and increase of lesions (in negative values) for each hamster in each treatment group are summarized in Table 3. With compound $\mathbf{4 d}$, the percentages of improvement in the three hamsters that were not cured were close to $80 \%$, while in the hamsters treated with compounds $\mathbf{4 b}$ and $\mathbf{4 c}$, the improvement percentages in the four hamsters were not cured were between $40.6-90.3 \%$. In the group treated with compound $\mathbf{4 a}$, the percentages of improvement ranged between 58.9-88.7\% (see Table 3 ). With compounds $4 \mathrm{a}$ and $\mathbf{4 f}$, there were failures in the treatment, as evidenced by percentages of reduction of the lesion less than $10 \%$ and even negative values, corresponding to an increase in the size of the lesion (see Table 3 ).

Table 3. Effect of treatment with compounds $4 a-f$ on the size of the lesion.

\begin{tabular}{|llllll|}
\hline Compounds / hamster \# & \multicolumn{5}{c|}{ Lesion size reduction (\%) } \\
\cline { 2 - 6 } & 1 & 2 & 3 & 4 & 5 \\
\hline 4a & 58.9 & 88.7 & 6.0 & 88.7 & 69.0 \\
\hline 4b & 58,8 & 90,3 & 56,6 & 100 & 76,4 \\
\hline 4c & 100 & 68.2 & 79.6 & 40.6 & 85.6 \\
\hline $4 d$ & 79.1 & 100 & 100 & 78.1 & 79.5 \\
\hline $4 e$ & 54.9 & 69.0 & 39.7 & 67.8 & $-1.1^{a}$ \\
\hline 4f & -249 & 100 & 9.4 & -126 & 2.2 \\
\hline MA & 100 & 100 & 78.0 & 100 & 100 \\
\hline
\end{tabular}


The values are the reduction percentages, comparing the size at the end of the study with respect to the size before the treatment. Negative values indicate an increase in the size of the lesion at the end of the study. The appearance of the lesions before treatment and at the end of the study in a representative hamster in each treatment with compounds $\mathbf{4 a - f}$ are shown in Figure $\mathbf{S} 1$ in supplementary information.

\subsubsection{Effect of treatment with cream formulation $4 a-f$ on the body weight of hamsters with cutaneous leishmaniasis.}

No loss in average body weight in hamsters was observed during the study; therefore, no detrimental effect on hamster weight or toxic effects could be attributed to compound treatment. According to the weight of the animals at the beginning and during the study, no significant differences were observed in the groups of hamsters treated with compounds or MA. (Figure S2 in supplementary information) Likewise, no alterations were observed in the levels of ALT, BUN, and serum creatinine, measured 8 days after treatment with compounds $\mathbf{4 a}-\mathbf{f}$ or MA, which suggests that liver and kidney function were not affected in a way that could be attributed to these treatments.

\section{Molecular docking simulation}

According to the obtained results shown in Table 4, Figure 2, and Tables S1-S2 (see in supplementary information). The molecular docking experiments showed more favorable interactions, as well as ligand efficiency with $L m D H O D H$ target. In general, the low $K_{d}$ values indicate strong binding of the molecule to the protein. Therefore, compounds $4 a-$ f exhibited promising activity against intracellular amastigotes of $L$. ( $V$ ) panamensis, as these compounds formed a stable complex with each target studied. Table $\mathbf{4}$ also shows that $\mathbf{4 b}$ and $\mathbf{4 d}$ presented better interaction energies in $\mathbf{2 -}$ arylquinoline- $L m D H O D H$ interactions. According to the experimental data, compounds $\mathbf{4 b}$ - $\mathbf{d}$ were able to produce healing and improvement of the lesions in the hamsters after being treated. In Tables 5 and 6 , the interacting residues for both targets are summarized. Herein, it is possible to observe some residue differences in the binding modes of the active compounds.

Table 4. Molecular docking results for $\mathbf{4 a - f}$ in the $L m D H O D H$ and $L m T X N P x$. Intermolecular docking energy values $\left(\Delta E_{\text {binding }}\right), K_{d}$ values, and calculated Ligand Efficiency $(L E)$ for the $L m D H O D H$ and $L m T X N P x$ complexes. 


\begin{tabular}{|c|c|c|c|c|c|c|}
\hline \multirow[t]{3}{*}{ Compound } & \multicolumn{2}{|l|}{ Docking Results } & \multicolumn{4}{|c|}{ Ligand Efficiency } \\
\hline & \multirow{2}{*}{ 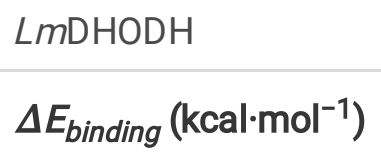 } & \multirow{2}{*}{$\begin{array}{l}L m T X N P x \\
\Delta E_{\text {binding }}\left(\mathrm{kcal} \cdot \mathrm{mol}^{-1}\right)\end{array}$} & \multicolumn{2}{|c|}{ LmDHODH } & \multicolumn{2}{|c|}{ LmTXNPx } \\
\hline & & & $K_{d}$ & $L E\left(\mathrm{kcal} \cdot \mathrm{mol}^{-1}\right)$ & $K_{d}$ & $L E\left(\mathrm{kcal}^{\prime} \mathrm{mol}^{-1}\right)$ \\
\hline $4 a$ & -7.7 & -7.6 & $\begin{array}{c}2.27 \\
10^{-6}\end{array}$ & 0.35 & $\begin{array}{c}2.69 \\
10^{-6}\end{array}$ & 0.35 \\
\hline $4 b$ & -8.3 & -7.5 & $\begin{array}{c}8.26 \\
10^{-7}\end{array}$ & 0.36 & $\begin{array}{c}3.18 \\
10^{-6}\end{array}$ & 0.33 \\
\hline $4 c$ & -7.6 & -7.1 & $\begin{array}{c}2.69 \\
10^{-6}\end{array}$ & 0.32 & $\begin{array}{c}6.26 \\
10^{-6}\end{array}$ & 0.30 \\
\hline $4 d$ & -8.3 & -7.1 & $\begin{array}{c}8.26 \\
10^{-7}\end{array}$ & 0.33 & $\begin{array}{c}6.26 \\
10^{-6}\end{array}$ & 0.28 \\
\hline $4 e$ & -7.7 & -7.4 & $\begin{array}{c}2.27 \\
10^{-6}\end{array}$ & 0.33 & $\begin{array}{c}3.77 \\
10^{-6}\end{array}$ & 0.32 \\
\hline $4 f$ & -7.4 & -6.8 & $\begin{array}{c}3.77 \\
10^{-6}\end{array}$ & 0.30 & $\begin{array}{c}1.03 \\
10^{-5}\end{array}$ & 0.27 \\
\hline
\end{tabular}

\section{ADMET Properties}

The goal of calculating ADMET profiles is to provide, with reasonable accuracy, a preliminary prediction of the in vivo behaviour of a compound, in order to assess its potential to become a drug ${ }^{28}$. The molecules used in this study were submitted to the calculation of their absorption, distribution, metabolism, excretion, and toxicological properties (ADMET). Furthermore, physicochemical properties, such as molecular hydrogen bond acceptor $(H B A)$, hydrogen bond donor $(H B D)$, weight $(M W)$, topological polar surface area $(T P S A)$, rotatable bond count $(R B)$, octanol/water partition coefficient $(\log P)$, and Molar Refractivity $(M R)$ were calculated, using the SwissADME webserver ${ }^{29}$. Compound toxicological properties were analysed taking into account the Lipinski, Ghose, Veber, and Pfizer toxicity empirical rules.

In order to assess whether molecules can be selected as potential $4 a-f$ inhibitors, we calculated some pharmacokinetic properties (Table 5). These results were contrasted against Lipinski ${ }^{30}, \mathrm{Ghose}^{31}, \mathrm{Veber}^{32}$, and Pfizer ${ }^{33}$ rules. If any of the compounds only satisfied two of the rules of Lipinski and Ghose, we took that compound as precautionary; if it satisfied only one rule, then this molecule is not a good candidate. Following Veber's rules, if a compound does not meet any of these parameters, then it is not a good drug candidate. Pfizer's toxicity rules were also taken into account-if any of our ligands did not meet these parameters, then it was not considered a good drug candidate. According to Table 5, it is observable that the candidates were within the range of expected values for the Lipinski's and Gelovani's parameters. Therefore, their bioavailability and absorption are not poor, and they were expected to be orally active. Additionally, the Boiled-egg model (see Figure $\mathbf{5}$ in supplementary information) was used to calculate the lipophilicity and polarity of these molecules. The results showed that all of the studied 2arylquinolines are highly absorbable at the blood-brain barrier, while not being absorbable in the gastrointestinal tract. Finally, the ADMET properties suggested that these compounds may be safe compounds for use as leishmaniasis inhibitors (see Figure $\mathbf{4}$ in supplementary information).

Table 5.ADMET molecular descriptors of compounds designed as leishmaniasis inhibitors. 


\begin{tabular}{|llllllllllll|}
\hline Compound & $\boldsymbol{M W}(\mathbf{g} / \mathrm{mol})$ & $\mathbf{M}$ & LogP & HBA & HBD & TPSA $\left(\AA^{2}\right)$ & LR & GR & VR & PR & $\begin{array}{l}\text { Synth. } \\
\text { Acce. }\end{array}$ \\
\hline 4a & 289.33 & 88.61 & 3.88 & 3 & 0 & 39.19 & 0 & 0 & 0 & 0 & 2.53 \\
\hline 4b & 305.33 & 90.64 & 3.51 & 4 & 1 & 59.42 & 0 & 0 & 0 & 0 & 2.64 \\
\hline 4c & 319.35 & 95.1 & 3.84 & 4 & 0 & 48.42 & 0 & 0 & 0 & 0 & 2.78 \\
\hline 4d & 335.35 & 97.13 & 3.48 & 5 & 1 & 68.65 & 0 & 0 & 0 & 0 & 2.88 \\
\hline 4e & 368.22 & 96.31 & 4.46 & 3 & 0 & 39.19 & 0 & 0 & 0 & 0 & 2.68 \\
\hline 4f & 333.38 & 99.91 & 4.16 & 4 & 0 & 48.42 & 0 & 0 & 0 & 0 & 2.66 \\
\hline
\end{tabular}

${ }^{1}$ LR: Lipinski Rules, GR: Ghose Rules, VR: Veber Rules, PR; Pfizer Rules, and Synth. Acce.: Synthetic accessibility. ${ }^{2} M W$. Molecular weight, MR: Molar Refractivity, LogP. octanol/water partition coefficient, HBA: Hydrogen Bond Acceptor, $H B D$. Hydrogen Bond Donor, TPSA: Topological Polar Surface Area, and RB: Rotatable Bond.

\section{Molecular dynamic simulations.}

The molecular docking results allowed us to recognize that the LmDHODH-ligand complexes showed more favourable interactions and ligand efficiency. Therefore, the finally selected position of the ligands, based on the docking score and predicted binding energy, was studied to describe the molecular interactions of LmDHODH with the bound ligands over time. In this context, molecular dynamics (MD) simulation showed the dynamic behaviour of the LmDHODH-ligand molecular system, assessing the stability of the complex. The most highly stable conformations for the LmDHODH system were subjected to the study of molecular dynamics with the CHARMM force field. Thus, six LmDHODH complexes were built for each model, that were confined inside a periodic simulation box. The water model TIP3P ${ }^{34}$, with 12.552 molecules, was utilized as solvent. Moreover, $\mathrm{Na}^{+}$and $\mathrm{Cl}^{-}$ions were added, for neutralizing the systems and maintaining an ionic concentration of $0.15 \mathrm{~mol} \cdot \mathrm{L}^{-1}$. Full geometric optimizations of the two molecules were done by density functional theory method by M05-2X ${ }^{35}-\mathrm{D} 3^{36}$, in conjunction with the 6-31G(d,p) basis set. The compounds (4a-f) and flavin mononucleotide (FMN) were parametrized using the LigParGen web server and the OPLS-AA/1.14*CM1A(-LBCC) force field parameters were used for organic ligands ${ }^{37-39}$. The partial charges were determined for each ligand by the restrained electrostatic potential (RESP) model ${ }^{40}$. MD simulations were realized using the modelled CHARMM22 and CHARMM36 force fields ${ }^{41,42}$ within the NAMD software ${ }^{43} \cdot 20,000$ steps of conjugate-gradient energy minimization were included for each system, followed by simulations of $5 \mathrm{~ns}$ with fixed protein backbone atoms, and a gradual release of the backbone over 100,000 ps with restraints from 10 to 0.0 $\mathrm{kcal} \cdot \mathrm{mol}^{-1} \AA^{-2}$. The total duration of simulation was $\sim 70 \mathrm{~ns}$ per system. During the molecular dynamic's simulations, motion equations were integrated with 2 femtoseconds time-steps in the NPT ensemble at a pressure of $1 \mathrm{~atm}$.

SHAKE algorithm was applied to all hydrogen atoms, and a $12 \AA$ Van der Waals cut-off was set. Temperature was set to $310 \mathrm{~K}$, by the Nosé-Hoover thermostat method with a relaxation time of $1 \mathrm{ps}$. Pressure was controlled at $1 \mathrm{~atm}$ by using a Nosé-Hoover-Langevin piston. Long-range electrostatic forces were considered by the particle-mesh Ewald approach. MD runs data was collected every $1 \mathrm{ps}$. Molecular visualization of the systems and trajectory analysis was done using the VMD software package ${ }^{44}$. The final snapshots of the molecular dynamics simulations are illustrated in Figure $\mathbf{S} \mathbf{6}$ (see supplementary information)

Previous studies have shown that the FMN molecule plays a functional role in the active site of $L m D H O D H$, acting as a stabilizing cofactor of the active site and forming an aromatic box whose function is to stabilize the ligand $\mathrm{d}^{45-47}$. 
The molecular simulation results showed differences in the binding and interaction of compounds $\mathbf{4 a}, \mathbf{4 b}, \mathbf{4 c}, \mathbf{4 d}$, and $\mathbf{4 f}$ with the main binding site (BP1); see Figures $\mathbf{S 6}$ and $\mathbf{S 7}$ in supplementary information)

The results also show that, throughout the simulation trajectory, compound 4a remained stable in this original binding site (where the catalytic function of $\mathrm{LmDHODH}$ is found, regions S1-S5); interacting in a stable way with FMN and representing a 10\% interaction throughout the molecular simulation (see Figure S8 in supplementary information).

On the other hand, compounds $\mathbf{4 b}, \mathbf{4 c}, \mathbf{4 d}$, and $\mathbf{4 f}$ were stably located in a position close to the binding site of LmDHODH (BP2 site), with a low percentage of participation of the residues in the regions S1-S5 (see Figure 10); this fluctuation space made a null interaction with the FMN cofactor, (see Figures S6 and S7 in supplementary information). For the case of compound $\mathbf{4 e}$ at 24 ns of the trajectory, it left the $L m D H O D H$ binding site and remained free in the solvated medium (see Figures $\mathbf{S 6}$ and $\mathbf{S 7}$ in supplementary information).

Molecular dynamics simulations showed that $\angle m D H O D H$ residues directly interacted with the ligands $(\mathbf{4 a}-\mathbf{f})$. The most frequent $\angle m D H O D H$ residues are illustrated in Figure $\mathbf{S 8}$ (see in supplementary information). Additionally, the potential inhibitors evaluated here interacted with the before-mentioned pockets (BP1 and BP2) through electrostatic and hydrophobic interactions. In the case of compound $\mathbf{4 a}$, it showed interactions with the S1-S4 regions, with the residues gly71, leu72, ser100, ser130, gln139, asn128, asn195, phe218, gly198, ser196, and ile197 (see Figure S8 in supplementary information). These coincide with those previously reported by the scientific community, which are the S1, S2, S3, and S4 sites, thus validating the protocol used in this work ${ }^{45,47-49}$. For compounds $\mathbf{4 b}$, 4c, $4 \mathbf{d}$, and 4f, a low percentage was shown, with the only interaction region being S2, involving residues leu102, leu72, val140, asn107, cys150, asn107, val140, and ser100; the other residue interactions were distributed at the BP2 binding site. In the case of compound $4 \mathrm{e}$, there was no stable interaction at the main binding site, causing the escape of this compound into the solvated medium during the molecular simulation. These results document that compounds $4 \mathbf{a}-\mathbf{f}$ are reversible inhibitors of $L m D H O D H$.

\section{Free Energy Calculation}

The molecular MM/GBSA method was employed, in order to estimate the binding free energy of the LmDHODH complexes. For calculations from a total of $70 \mathrm{~ns}$ of MD, the last $50 \mathrm{~ns}$ were extracted for analysis, and the explicit water molecules and ions were removed. The MM/GBSA analysis was performed on three subsets of each system: the protein alone, the ligand alone, and the complex (protein-ligand). For each of these subsets, the total free energy $\left(\Delta G_{\text {tot }}\right)$ was calculated as follows:

$$
\Delta G_{t o t}=E_{M M}+G_{\text {solv }}-T \Delta S_{\text {conf }}
$$

where $E_{M M}$ is the bonded and Lennard-Jones energy terms, $G_{\text {solv }}$ is the polar contribution of solvation energy and non-polar contribution to the solvation energy, $T$ is the temperature, and $\Delta S_{\text {conf }}$ corresponds to the conformational entropy ${ }^{50}$. Both $E_{M M}$ and $G_{\text {solv }}$ were calculated using the NAMD software with the generalized Born implicit solvent model $^{51,52} . \Delta G_{\text {tot }}$ was calculated as a linear function of the solvent-accessible surface area, which was calculated with a probe radius of $1.4 \AA^{53}$. The binding free energy of LmDHODH and ligand complexes $\left(\Delta G_{b i n d}\right)$ were calculated by the difference, where $\Delta G_{t o t}$ values are the averages over the simulation:

$$
\Delta G_{\text {bind }}=\Delta G_{\text {tot }}(\text { complex })-\Delta G_{\text {tot }}(\text { LmDHODH })-\Delta G_{\text {tot }}(\text { ligand }) .
$$


The binding free energy (MM/GBSA) was computed after the MD simulation, considering the last 70 ns for all of the complexes; the results are given in Table 4. Compound $\mathbf{4 d}$ had a binding free energy of $-30.05 \mathrm{kcal}^{-} \mathrm{mol}^{-1}$ with the LmDHODH enzyme, while compound $\mathbf{4 b}$ showed a comparable binding free energy of $-25.73 \mathrm{kcal}^{\circ} \cdot \mathrm{mol}^{-1}$. In the case of compounds $\mathbf{4 a}$ and $\mathbf{4} \mathbf{c}$, they showed relatively higher binding energy, with values of $-22.32 \mathrm{kcal}^{-\mathrm{mol}^{-1}}$ and -21.13 $\mathrm{kcal} \cdot \mathrm{mol}^{-1}$, respectively. Compounds $\mathbf{4 e}$ and $\mathbf{4 f}$ had the highest binding energy values $\left(-11.42 \mathrm{kcal}^{\prime} \mathrm{mol}^{-1}\right.$ and -18.59 $\mathrm{kcal} \cdot \mathrm{mol}^{-1}$, respectively), indicating the low stability of these compounds at the $\angle m D H O D H$ binding site; (see Figures S7 and $\mathbf{S 8}$ in supplementary information). The results obtained from MM/GBSA (see Table 6) calculations also demonstrated that compound $\mathbf{4 a}$ had a higher binding energy than compound $\mathbf{4 d}$, with an absolute difference of 7.73 $\mathrm{kcal} \cdot \mathrm{mol}^{-1}$. This difference was due to the interaction with the cofactor flavin mononucleotide. In particular, the $4 \mathrm{a}$ compound had better activity at both the experimental and in silico levels.

Table 6. Predicted binding free energies $\left(\mathrm{kcal} \cdot \mathrm{mol}^{-1}\right)$ and individual energy terms, calculated from molecular dynamics simulation through the MM/GBSA protocol for $L m D H O D H$ complexes.

\begin{tabular}{|lllll|}
\hline Compounds & \multicolumn{4}{c|}{ Calculated Free Energy Decomposition $\left(\mathrm{kcal} \cdot \mathrm{mol}^{-1}\right.$ ) } \\
\cline { 2 - 5 } & $\Delta G_{\text {binding }}$ & $\Delta E_{v d W}$ & $\Delta E_{\text {elect }}$ & $\Delta E_{\text {pot }}$ \\
\hline 4a & $-22.32 \pm 0.13$ & $-33.10 \pm 0.16$ & $15.43 \pm 0.07$ & $-17.66 \pm 0.12$ \\
\hline 4b & $-25.73 \pm 0.08$ & $-31.52 \pm 0.09$ & $10.02 \pm 0.03$ & $-21.49 \pm 0.07$ \\
\hline 4c & $-21.13 \pm 0.13$ & $-29.29 \pm 0.16$ & $12.19 \pm 0.08$ & $-17.09 \pm 0.12$ \\
\hline 4d & $-30.05 \pm 0.08$ & $-37.33 \pm 0.08$ & $11.88 \pm 0.03$ & $-25.44 \pm 0.08$ \\
\hline 4e & $-11.42 \pm 0.12$ & $-16.73 \pm 0.16$ & $7.10 \pm 0.06$ & $-9.62 \pm 0.10$ \\
\hline 4f & $-18.59 \pm 0.19$ & $-25.35 \pm 0.20$ & $10.43 \pm 0.07$ & $-14.92 \pm 0.17$ \\
\hline
\end{tabular}

\section{Conclusion}

Compounds $\mathbf{4 a - f}$ showed promising in vitro activity against intracellular amastigotes of $L$. (V) panamensis. A cream formulation containing $1 \%$ of compounds $\mathbf{4 b} \mathbf{b} \mathbf{d}$ was able to produce healing and improvement of lesions in hamsters after treatment. It is noteworthy that there was a correlation between the results of the leishmanicidal activity in vitro and in vivo, demonstrating the promising activity of the compounds; likewise, the administration of the compounds during the study did not generate obvious signs of toxicity or significant weight loss in the treated animals. These results suggest that the compounds synthesized in this work, especially $4 b-d$, are promising and could be considered therapeutic targets to be evaluated in future studies for the treatment of cutaneous Leishmaniasis. Molecular dynamics (MD) simulations and MM/GBSA studies revealed that the compound 4 a has a preferential interaction with the cofactor flavin mononucleotide, suggesting better activity at the in silico level, which was confirmed by our experimental results. A computational docking study showed that molecules $\mathbf{4 b}$ and $\mathbf{4 d}$ present better interaction energies in 2-arylquinoline- $L m D H O D H$ interactions, in agreement with the experimental data regarding the treatment of hamster lesions. Finally, we predicted that the synthesized 2-arylquinolines are absorbable at the blood-brain barrier, but they have no action in the gastrointestinal tract.

\section{Declarations}

\section{Conflict of interest}

Page 15/22 
The authors confirm that the content this article has no conflicts of interest.

\section{Acknowledgments}

This work was supported by University of Cordoba and University of Antioquia. P.C.L. Thanks also to Universidad Andres Bello and Universidad de Santiago de Chile, for the funding through the postdoctoral project [POSTDOC_DICYT, Code 0921SP_POSTDOC].

\section{Author contributions}

R.E.S and C.G.T. Synthesis and chemical identification of compounds. S.M.R, T.P and J.M. Evaluation of biological activity in vitro e in vivo. C.Z, O.Y and P.C.L. Completion of theoretical studies.

\section{References}

1. de Mello, M. V. P. et al. A comprehensive review of chalcone derivatives as antileishmanial agents. European Journal of Medicinal Chemistry, 150, 920-929 (2018).

2. Singh, N., Mishra, B. B., Bajpai, S., Singh, R. K. \& Tiwari, V. K. Natural product based leads to fight against leishmaniasis. Bioorg. Med. Chem, 22, 18-45 (2014).

3. Hernández-Bojorge, S. E., Blass-Alfaro, G. G., Rickloff, M. A., Gómez-Guerrero, M. J. \& Izurieta, R. Epidemiology of cutaneous and mucocutaneous leishmaniasis in Nicaragua. Parasite Epidemiology and Control, 11, e00192 (2020).

4. Akbari, M., Oryan, A. \& Hatam, G. Immunotherapy in treatment of leishmaniasis. Immunol. Lett, 233, 80-86 (2021).

5. Chanquia, S. N. et al. Synthesis and biological evaluation of new quinoline derivatives as antileishmanial and antitrypanosomal agents. Bioorg. Chem, 83, 526-534 (2019).

6. Sharma, R. et al. Triazino indole-quinoline hybrid: A novel approach to antileishmanial agents. Bioorg. Med. Chem. Lett, 24, 298-301 (2014).

7. L, P., H, G. \& C, H., A, V. \& Synthesis, characterization, and antileishmanial activities of gold(I) complexes involving quinoline functionalized N-heterocyclic carbenes. European journal of medicinal chemistry, 94, 22-29 (2015).

8. Kawakami, M. Y. M. et al. Efficacy of nanoemulsion with Pterodon emarginatus Vogel oleoresin for topical treatment of cutaneous leishmaniasis. Biomed. Pharmacother, 134, 111109 (2021).

9. Briones Nieva, C. A. et al. An appraisal of the scientific current situation and new perspectives in the treatment of cutaneous leishmaniasis. Acta Trop, 221, 105988 (2021).

10. Sousa, J. K. T. et al. A chloroquinoline derivate presents effective in vitro and in vivo antileishmanial activity against Leishmania species that cause tegumentary and visceral leishmaniasis. Parasitol. Int, 73, 101966 (2019).

11. Nafari, A. et al. Nanoparticles: New agents toward treatment of leishmaniasis. Parasite Epidemiology and Control, 10, e00156 (2020).

12. Tiuman, T. S., Santos, A. O., Ueda-Nakamura, T., Filho, B. P. D. \& Nakamura, C. V. Recent advances in leishmaniasis treatment. International Journal of Infectious Diseases, 15, e525-e532 (2011).

13. Marella, A. et al. Quinoline: A versatile heterocyclic. Saudi Pharmaceutical Journal, 21, 1-12 (2013).

14. Hu, Y. Q. et al. Quinoline hybrids and their antiplasmodial and antimalarial activities. European Journal of Medicinal Chemistry, 139, 22-47 (2017). 
15. Kaur, K., Jain, M., Reddy, R. P. \& Jain, R. Quinolines and structurally related heterocycles as antimalarials. European Journal of Medicinal Chemistry, 45, 3245-3264 (2010).

16. Espinosa, R. et al. Synthesis and evaluation of the in vitro and in vivo antitrypanosomal activity of 2styrylquinolines. Heliyon, 7, e07024 (2021).

17. García, P. et al. Evaluation of the Trypanocidal, Cytotoxic and Genotoxic Activity of Styrylquinoline Analogs. http://dx.doi.org/10.1179/joc.2010.22.3.169 22, 169-174 (2013)

18. Torres, O. L. et al. Sinthesis of styrylquinolines with Leishmanicidal potential in vitro on Leishmania (Viannia) panamensis. Información tecnológica, 31, 3-12 (2020).

19. Cantero-López, P., Restrepo, S. M. R., Yañez, O., Zúñiga, C. \& Santafé-Patiño, G. G. Theoretical study of new LmDHODH and LmTXNPx complexes: structure-based relationships. Structural Chemistry $202032: 1$ 32, 167-177 (2020)

20. Espinosa, R., Torres, O. \& Robledo, S. M.Patente de Invención, Superintendencia de Industria y Comercio, Colombia. (2020)

21. Prathipati, S., Aangothu, S. R., Munnangi, S. R., Krishna Khandapu, B. M. \& Bollikolla, H. B. Volumetric, ultrasonic, spectroscopic, and molecular dynamics simulations studies of molecular interactions in binary mixtures of [EMIm][NTf2] with 2-propoxyethanol at temperatures from 298.15 to $318.15 \mathrm{~K}$. Journal of Chemical and Engineering Data, 65, 3566-3578 (2020).

22. Jabbari, F., Saedodin, S. \& Rajabpour, A. Experimental Investigation and Molecular Dynamics Simulations of Viscosity of CNT-Water Nanofluid at Different Temperatures and Volume Fractions of Nanoparticles. Journal of Chemical and Engineering Data, 64, 262-272 (2019).

23. Pattar, S. V., Adhoni, S. A., Kamanavalli, C. M. \& Kumbar, S. S. In silico molecular docking studies and MM/GBSA analysis of coumarin-carbonodithioate hybrid derivatives divulge the anticancer potential against breast cancer. Beni-Suef University Journal of Basic and Applied Sciences 2020 9:1 9, 1-10 (2020)

24. Chandrasekaran, B., Abed, S. N., Al-Attraqchi, O., Kuche, K. \& Tekade, R. K. Computer-Aided Prediction of Pharmacokinetic (ADMET) Properties. Dosage Form Design Parameters, 2, 731-755 (2018).

25. Coa, J. C. et al. Synthesis, leishmanicidal, trypanocidal and cytotoxic activity of quinoline-hydrazone hybrids. European Journal of Medicinal Chemistry, 101, 746-753 (2015).

26. Botero Aguirre, J. P., Restrepo Hamid, A. M. \& Botero Aguirre, J. P. Amphotericin B deoxycholate versus liposomal amphotericin B: effects on kidney function. Database Syst, 2015, CD010481 (2015).

27. Li, C. et al. Recent progress in drug delivery. Acta Pharmaceutica Sinica B, 9, 1145-1162 (2019).

28. Yu, H. \& Adedoyin, A. ADME-Tox in drug discovery: Integration of experimental and computational technologies., 8, 852-861 (2003).

29. Daina, A., Michielin, O., Zoete, V. \& SwissADME A free web tool to evaluate pharmacokinetics, drug-likeness and medicinal chemistry friendliness of small molecules. Sci. Rep, 7, 1-13 (2017).

30. Lipinski, C. A., Lombardo, F., Dominy, B. W. \& Feeney, P. J. Experimental and computational approaches to estimate solubility and permeability in drug discovery and development settings. Advanced drug delivery reviews, 46, 3-26 (2001).

31. Ghose, A. K., Viswanadhan, V. N. \& Wendoloski, J. J. A Knowledge-Based Approach in Designing Combinatorial or Medicinal Chemistry Libraries for Drug Discovery. 1. A Qualitative and Quantitative Characterization of Known Drug Databases. Journal of Combinatorial Chemistry, 1, 55-68 (1999).

32. Veber, D. F. et al. Molecular properties that influence the oral bioavailability of drug candidates. Journal of medicinal chemistry, 45, 2615-2623 (2002). 
33. Hughes, J. D. et al. Physiochemical drug properties associated with in vivo toxicological outcomes. Bioorg. Med. Chem. Lett, 18, 4872-4875 (2008).

34. Neria, E., Fisher, S. \& Karplus, M. Simulation of activation free energies in molecular systems. Journal of Chemical Physics, 105, 1902-1921 (1996).

35. Zhao, Y., Schultz, N. E. \& Truhlar, D. G. Design of Density Functionals by Combining the Method of Constraint Satisfaction with Parametrization for Thermochemistry, Thermochemical Kinetics, and Noncovalent Interactions. Journal of Chemical Theory and Computation, 2, 364-382 (2006).

36. Grimme, S., Ehrlich, S. \& Goerigk, L. Effect of the damping function in dispersion corrected density functional theory. Journal of Computational Chemistry, 32, 1456-1465 (2011).

37. Dodda, S., Vilseck, L. Z., Tirado-Rives, J., Jorgensen, L. \& J. \& W. 1.14CM1A-LBCC: Localized Bond-Charge Corrected CM1A Charges for Condensed-Phase Simulations. The Journal of Physical Chemistry B, 121, 38643870 (2017).

38. Dodda, L. S., Cabeza de Vaca, I., Tirado-Rives, J. \& Jorgensen, W. L. LigParGen web server: an automatic OPLS-AA parameter generator for organic ligands. Nucleic Acids Res, 45, W331-W336 (2017).

39. Jorgensen, W. L. \& Tirado-Rives, J. Potential energy functions for atomic-level simulations of water and organic and biomolecular systems. Proceedings of the National Academy of Sciences of the United States of America, 102, 6665-6670 (2005).

40. Bayly, C. I., Cieplak, P., Cornell, W. D. \& Kollman, P. A. A well-behaved electrostatic potential based method using charge restraints for deriving atomic charges: The RESP model. Journal of Physical Chemistry, 97, 10269-10280 (1993).

41. MacKerell, D. All-Atom Empirical Potential for Molecular Modeling and Dynamics Studies of Proteins. The Journal of Physical Chemistry B, 102, 3586-3616 (1998).

42. Huang, J. \& MacKerell, A. D. Jr CHARMM36 all-atom additive protein force field: Validation based on comparison to NMR data. Journal of Computational Chemistry, 34, 2135-2145 (2013).

43. Elsevier https://www.sciencedirect.com/science/article/pii/S0021999199962010

44. Humphrey, W., Dalke, A. \& Schulten, K. VMD: visual molecular dynamics. Journal of Molecular Graphics, 14, 3338 (1996).

45. Cordeiro, A. T., Feliciano, P. R., Pinheiro, M. P. \& Nonato, M. C. Crystal structure of dihydroorotate dehydrogenase from Leishmania major., 94, 1739-1748 (2012).

46. Feliciano, P. R., Cordeiro, A. T., Costa-Filho, A. J. \& Nonato, M. C. Cloning, expression, purification, and characterization of Leishmania major dihydroorotate dehydrogenase. Protein Expression and Purification, 48, 98-103 (2006).

47. Cheleski, J. et al. Novel insights for dihydroorotate dehydrogenase class 1A inhibitors discovery. European Journal of Medicinal Chemistry, 45, 5899-5909 (2010).

48. Ochoa, R. et al. Drug search for leishmaniasis: a virtual screening approach by grid computing. Journal of Computer-Aided Molecular Design, 30, 541-552 (2016).

49. Ogungbe, I. V., Erwin, W. R. \& Setzer, W. N. Antileishmanial phytochemical phenolics: Molecular docking to potential protein targets. Journal of Molecular Graphics and Modelling, 48, 105-117 (2014).

50. Hayes, J. M., Archontis, G. \& MM-GB(PB )SA Calculations of Protein-Ligand Binding Free Energies. in Molecular Dynamics (ed. Wang, L.) (IntechOpen, 2012). doi:10.5772/37107

51. Song, L., Lee, T. S., Zhu, C. \& York, D. M. \& Jr., K. M. M. Validation of AMBER/GAFF for Relative Free Energy Calculations. (2019) doi:10.26434/chemrxiv.7653434.v1 
52. Götz, A. W. et al. Routine Microsecond Molecular Dynamics Simulations with AMBER on GPUs. 1. Generalized Born. Journal of Chemical Theory and Computation, 8, 1542-1555 (2012).

53. Abroshan, H., Akbarzadeh, H. \& Parsafar, G. A. Molecular dynamics simulation and MM-PBSA calculations of sickle cell hemoglobin in dimer form with Val, Trp, or Phe at the lateral contact. Journal of Physical Organic Chemistry, 23, 866-877 (2010).

54. Herrera, N. et al. Genotoxicity and cytotoxicity of three microcystin-LR containing cyanobacterial samples from Antioquia. Colombia. Toxicon, 154, 50-59 (2018).

55. Pulido, S. A. et al. Improvement of the green fluorescent protein reporter system in Leishmania spp. for the in vitro and in vivo screening of antileishmanial drugs. Acta Trop, 122, 36-45 (2012).

56. Finney, D. J. Statisical logic in the monitoring of reactions to therapeutic drugs. Methods of information in medicine, 10, 237-245 (1971).

57. Insuasty, B. et al. An efficient synthesis of new caffeine-based chalcones, pyrazolines and pyrazolo[3,4-b] $[1,4]$ diazepines as potential antimalarial, antitrypanosomal and antileishmanial agents. European Journal of Medicinal Chemistry, 93, 401-413 (2015).

58. Frieden, T. R. et al. Morbidity and Mortality Weekly Report Guidelines for Safe Work Practices in Human and Animal Medical Diagnostic Laboratories Recommendations of a CDC-convened, Biosafety Blue Ribbon Panel Centers for Disease Control and Prevention MMWR Editorial and Production Staff MMWR Editorial Board(2012)

59. du Sert, N. P. et al. The arrive guidelines 2.0: Updated guidelines for reporting animal research.PLoS Biology18, (2020)

60. Robledo, S. M. et al. Cutaneous Leishmaniasis in the dorsal skin of hamsters: A useful model for the screening of antileishmanial drugs. Journal of Visualized Experiments, 62, e3533 (2012).

61. Brindisi, M. et al. Structure-based discovery of the first non-covalent inhibitors of Leishmania major tryparedoxin peroxidase by high throughput docking. Sci. Rep, 5, 1-10 (2015).

62. Aly, A. A. et al. New quinoline-2-one/pyrazole derivatives; design, synthesis, molecular docking, anti-apoptotic evaluation, and caspase-3 inhibition assay. Bioorg. Chem, 94, 103348 (2020).

63. Fiorillo, A., Colotti, G., Boffi, A., Baiocco, P. \& Ilari, A. The Crystal Structures of the Tryparedoxin-Tryparedoxin Peroxidase Couple Unveil the Structural Determinants of Leishmania Detoxification Pathway. PLoS Neglected Tropical Diseases, 6, e1781 (2012).

64. Trott, O. \& Olson, A. AutoDock Vina: improving the speed and accuracy of docking with a new scoring function, efficient optimization and multithreading. Journal of Computational Chemistry, 31, 455-461 (2010).

65. Stewart, J. J. P. MOPAC. (2016)

66. Stewart, J. J. P. Optimization of parameters for semiempirical methods V: Modification of NDDO approximations and application to 70 elements. Journal of Molecular Modeling, 13, 1173-1213 (2007).

67. Řezáč, J. \& Hobza, P. Advanced corrections of hydrogen bonding and dispersion for semiempirical quantum mechanical methods. Journal of Chemical Theory and Computation, 8, 141-151 (2012).

68. Dassault Systèmes, B. I. O. V. I. A. Discovery Studio Modeling Environment. (2017)

69. Sanner, M. F. Python: a programming language for software integration and development. Journal of Molecular Graphics and Modelling, 17, 55-84 (1999).

70. Berman, H. M. et al. The Protein Data Bank. Nucleic Acids Res, 28, 235-242 (2000).

71. Madhavi Sastry, G., Adzhigirey, M., Day, T., Annabhimoju, R. \& Sherman, W. Protein and ligand preparation: parameters, protocols, and influence on virtual screening enrichments. Journal of Computer-Aided Molecular Design, 27, 221-234 (2013). 
72. Morris, G. M. et al. Automated docking using a Lamarckian genetic algorithm and an empirical binding free energy function. Journal of Computational Chemistry, 19, 1639-1662 (1998).

73. Cantero-López, P., Restrepo, S. M. R., Yañez, O., Zúñiga, C. \& Santafé-Patiño, G. G. Theoretical study of new LmDHODH and LmTXNPx complexes: structure-based relationships. Structural Chemistry 2020 32:1 32, 167-177 (2020)

74. Abad-Zapatero, C. Ligand efficiency indices for effective drug discovery. Expert Opinion on Drug Discovery, 2, 469-488 (2007).

75. Abad-Zapatero, C. et al. Ligand efficiency indices for an effective mapping of chemico-biological space: the concept of an atlas-like representation., 15, 804-811 (2010).

76. Abad-Zapatero, C. Ligand Efficiency Indices for Drug Discovery. (Academic Press, 2013). doi:https://doi.org/10.1016/B978-0-12-404635-1.00009-8

77. Reynolds, C. H., Tounge, B. A. \& Bembenek, S. D. Ligand Binding Efficiency: Trends, Physical Basis, and Implications. Journal of Medicinal Chemistry, 51, 2432-2438 (2008).

78. Abad-Zapatero, C. Ligand Efficiency Indices for Drug Discovery. (Academic Press, 2013). doi:https://doi.org/10.1016/B978-0-12-404635-1.00009-8

79. Cavalluzzi, M. M., Mangiatordi, G. F., Nicolotti, O. \& Lentini, G. Ligand efficiency metrics in drug discovery: the pros and cons from a practical perspective. Expert Opinion on Drug Discovery, 12, 1087-1104 (2017).

80. Abad-Zapatero, C. Ligand efficiency indices for effective drug discovery. Expert Opinion on Drug Discovery, 2, 469-488 (2007).

81. Abad-Zapatero, C. et al. Ligand efficiency indices for an effective mapping of chemico-biological space: the concept of an atlas-like representation., 15, 804-811 (2010).

\section{Figures}


<smiles>CC(=O)Oc1ccccc1/C=C/c1ccc2ccccc2n1</smiles>

$4 a$<smiles>COc1cccc(/C=C/c2ccc3ccccc3n2)c1OC(C)=O</smiles>

$4 c$<smiles>CC(=O)Oc1ccc(Br)cc1/C=C/c1ccc2ccccc2n1</smiles>

4 e<smiles>CC(=O)Oc1ccccc1/C=C/c1ccc2cccc(O)c2n1</smiles>

$4 b$<smiles>COc1cccc(/C=C/c2ccc3cccc(O)c3n2)c1OC(C)=O</smiles>

$4 d$<smiles>CCOc1cc(/C=C/c2ccc3ccccc3n2)ccc1OC(C)=O</smiles>

$4 f$

Figure 1

Chemical structure of 2-arylquinolines analogues 4a-f

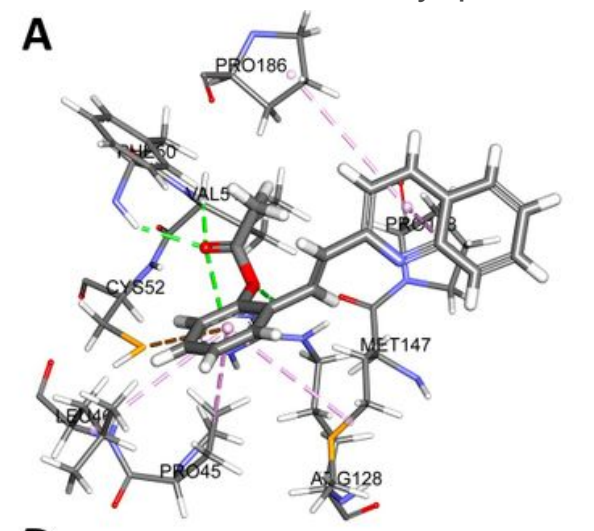

D

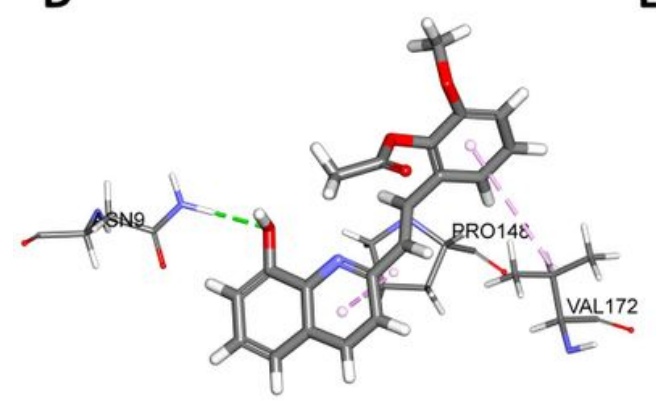

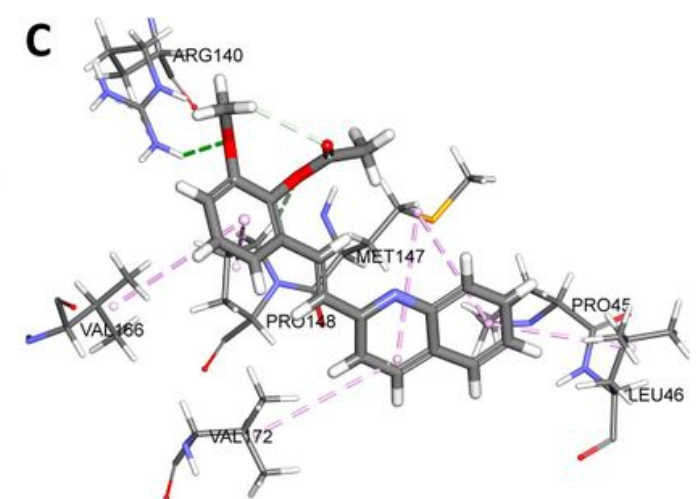

F

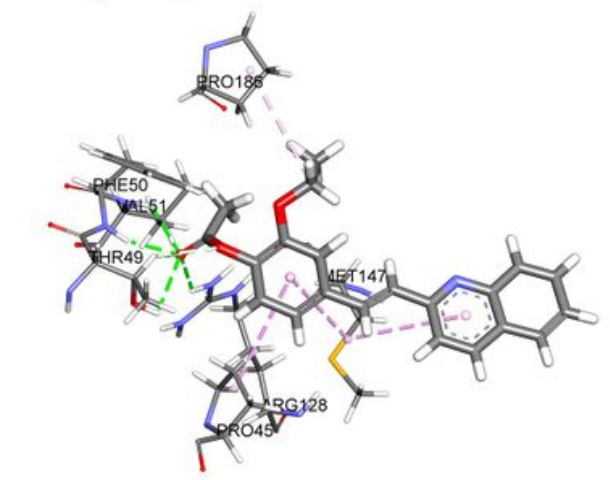

Figure 2 
Docking analysis for ligands $(A-F) 4 a-f$ bound to LmTXNPx. The surrounding amino acid residues in the binding pocket of LmTXNPx within $3 \AA$.

\section{Supplementary Files}

This is a list of supplementary files associated with this preprint. Click to download.

- Supplementarylnformation61120211.docx 